\title{
Inthrltgiiluer ftd)t
}

zum zweiten Band (I. Teil.)

\author{
$3^{\text {weites }} \mathfrak{B u}$ ư.

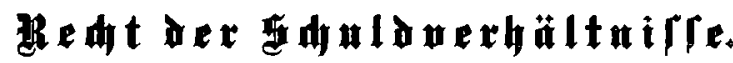

Illgemeiner Seil.

(Borbemerfungen, $\$ \$$ 241-432, crlüutert von Dr. \&. Suhlenbeaf.)

Siteratur im allgemeinen

Mblürzungen

Borbemertungen

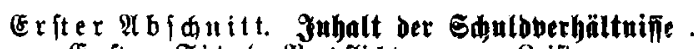

Eriter Titel: gerbflihtung aur Reiftung

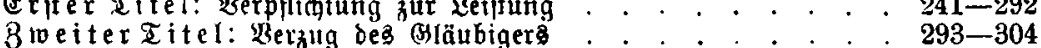

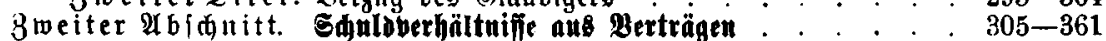

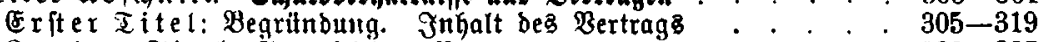

8 weiter it el: Begenfeitiger Bertrag. . . . . . . . . . 320-327

Dritter $\mathcal{L}_{\text {itel: }}$ Berfpredien ber Leiftung an einen Dritten. $\quad 328-335$

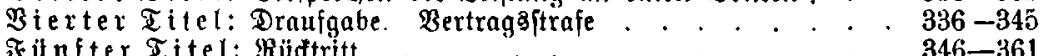

Fit $n$ it er $\mathfrak{T}$ it el: Rüdtritt

$346-361$

$362-397$

$372-386$

Er jiter I i tel: Erfülung

$387-396$

Dritter Iite l: Uufreønung

397

Bierter 茫tel: Erlaß̉

$398-413$

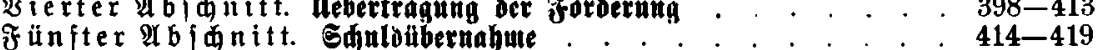

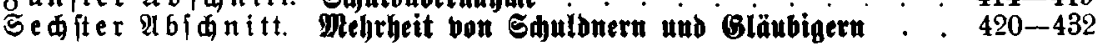

כelte

VII

1

18

18

204

218

224

254

294

312

332

356

366

394

414

439

442

481

\section{Sefonderer Seil.}

(Einleitung, \$\$ 433-580, erläutert von Ur. S. Soher.)

Siebenter Ab/由nitt. Cinzelue Sdulbuerbältuilie . . . . . . $433-853$

Einleitung

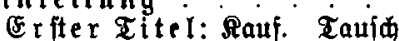

433்- $\dot{5} 1 \dot{5}$

I. $\mathfrak{A}$ ggemeine $\mathfrak{B}$ oridriften . . . . . . . . . . . . . . 433-458

II. Gewäbrleiftung wegeı Mängel ber Ṡade . . . . . . 459-493

Selte

555

555

558

III. Bejondere Arten Des Raufes . . . . . . . . . . 494-514

562

Bmetter Ettel: Sdentung. . . . . . . . . . . . . . . 516-534

785.

goter rat.

788

I. Miete

832

Der Galuǵ des "Befonderen Teils" und das "Mlphabetifipe Negifter" zum 2. Bande ift im 2. Teile enthalten. 